\title{
Can high-frequency mini-probe endoscopic ultrasonography predict outcome of endoscopic dilation in patients with benign esophageal strictures?
}

다(1)이우

\author{
Authors \\ Institutions \\ 1 Department of Gastroenterology, Post Graduate \\ Institute of Medical Education and Research, \\ Chandigarh, India \\ 2 Department of Radiodiagnosis, Post Graduate Institute \\ of Medical Education and Research, Chandigarh, India
}

Philip Daniel*, 1, Jayanta Samanta ${ }^{*}, 1$, Ajay Gulati², Pankaj Gupta1 ${ }^{1}$, Gaurav Muktesh ${ }^{1}$, Saroj K. Sinha1, Rakesh Kochhar ${ }^{1}$

Depth of involvement of the esophageal wall on endosonography using high frequency mini-probe (EUS-M) may predict response to dilation. This study evaluated EUS-M characteristics to predict response of ES to endoscopic dilation.

Patients and methods EUS-M was used to measure the total esophageal wall thickness (EWT), involved EWT, percen- submitted 26.2.2020

accepted after revision $\quad 8.6 .2020$

\section{Bibliography}

Endoscopy International Open 2020; 08: E1371-E1378

DOI 10.1055/a-1223-1377

ISSN 2364-3722

(c) 2020. The Author(s).

This is an open access article published by Thieme under the terms of the Creative Commons Attribution-NonDerivative-NonCommercial License, permitting copying and reproduction so long as the original work is given appropriate credit. Contents may not be used for commecial purposes, or adapted, remixed, transformed or built upon. (https://creativecommons.org/licenses/by-nc-nd/4.0/)

\section{Corresponding author}

Rakesh Kochhar, Department of Gastroenterology, Post Graduate Institute of Medical Education and Research, Chandigarh. Sector -12, Chandigarh - 160012, India Fax: +911722744401

dr_kochhar@hotmail.com

\section{ABSTRACT}

Background and study aims Endoscopic dilation is firstline management for benign esophageal strictures (ES). tage of involved wall and layers of wall involved in consecutive patients of benign ES. After a maximum of five sessions of endoscopic dilation, the cohort was divided into responders and refractory strictures. EUS-M characteristics were compared for underlying etiology as also between responders and refractory strictures.

Results Of the 30 strictures (17 females, age: 47.16 \pm 15.86 yrs.) 13 were anastomotic, eight corrosive, seven peptic and 2 others. Corrosive strictures had the highest involved EWT and percentage of involved wall $(3.51 \pm 1.36$ $\mathrm{mm}$; $76.38 \%)$ followed by anastomotic $(2.73 \pm 1.7 \mathrm{~mm}$; $65.54 \%)$ and peptic $(1.39 \pm 0.62 \mathrm{~mm} ; 40.71 \%) \quad(P=0.026$ and 0.021 respectively). After five dilations, 22 were classified as responders and eight as refractory. Wall involvement $>70 \%$ had a greater proportion of refractory strictures $(P=$ $0.019)$. Strictures with involved EWT of $\geq 2.85 \mathrm{~mm}$ required more dilations $(P=0.011)$. Fewer dilations were required for stricture resolution with only mucosal involvement compared to deeper involvement such as submucosa and muscularis propria (2.14 vs. $5.80 ; P=0.001)$.

Conclusion EUS-M evaluation shows that corrosive and anastomotic strictures have greater depth of involvement compared to peptic strictures. Depth of esophageal wall involvement in a stricture predicts response to dilation.

\section{Introduction}

Esophageal strictures (ES) are circumscribed narrowing of the esophageal lumen to a diameter $<13 \mathrm{~mm}$ which lead to dysphagia, difficulty in swallowing. Benign esophageal strictures (ES) are more common and can be due to various etiologies like corrosive ingestion, peptic disease, radiotherapy for head and neck cancers, and postoperative strictures. Endo-therapy is also

* These authors contributed equally first-line management for benign strictures. Dilation by bougie or balloon dilators has been the standard treatment for benign ES and generally the simple ones respond adequately to one to three dilations [1]. Complex strictures, however, are difficult to treat being longer $(>2 \mathrm{~cm})$, angulated or with severely stenosed lumen [2]. Approximately $20 \%$ to $30 \%$ of benign strictures can become refractory to endoscopic dilation, and as many as $50 \%$ in cases of corrosive strictures [3]. Factors determining response to endo-therapy have been the point of much research. 
Techniques that have been studied to predict response to endoscopic dilations include contrast-enhanced computed tomography (CECT) scans and endoscopic ultrasound (EUS). Esophageal wall thickness (EWT) on CECT has been found to correlate with response to dilation in one study [4] but not in another [5]. EUS, using radial probe, placed at the proximal margin of the stricture, has been used to predict response to dilation based on the depth of tissue injury, i.e. the number of layers of esophageal wall involved [6]. The main drawback of the radial EUS probe is that it may not generally be negotiable across the stricture segment, and hence, may result in inadequate characterization of esophageal wall involvement.

EUS mini-probes (EUS-M) are high-frequency $(12-20 \mathrm{MHz}$ ) three-dimensional (3D) catheter probes that can be easily negotiated across the stricture segment without dilation, enabling high-frequency image acquisition. There is only one study of EUS-M in patients with benign ES, wherein the authors showed that mucosal involvement required fewer endoscopic dilation sessions compared to deeper involvement [7] .

With a lack of data on use of EUS-M in evaluation and prediction of response of benign ES to dilation therapy, this study was planned as a proof-of-concept to analyze benign ES with EUS-M and identify characteristics that can help in predicting its response to dilation therapy.

\section{Patients and methods}

This was a prospective study of all consecutive patients with benign ES who presented to the Department of Gastroenterology in a tertiary care center with dysphagia between June 2019 and December 2019. Patients who had esophageal webs, stricture length $>6 \mathrm{~cm}$, malignant or post-radiation strictures or who had undergone prior endoscopic intervention were excluded. Written informed consent were obtained from all patients. The study was approved by the Institute ethics committee (ethics clearance number INT/IEC/2019/001416, dated 16.07.2019).

\section{Baseline evaluation}

All patients underwent barium esophagography to assess the site, number, and length of stricture(s) and associated gastric involvement. Each patient also underwent an esophagogastroduodenoscopy (EGD) evaluation using a gastroscope (Olympus GIF-H180; outer diameter $9.9 \mathrm{~mm}$.) for stricture site, number, length, and presence of ulceration. Stricture diameter was assessed by the size of the first balloon dilator used for dilation. The esophagus was divided into upper one-third (upper esophageal sphincter to $23 \mathrm{~cm})$, middle third $(23-31 \mathrm{~cm})$ and lower third $(31 \mathrm{~cm}$ to lower esophageal sphincter).

An EUS mini-probe (Olympus UM-DG20-31 R, freq. $20 \mathrm{MHz}$; diameter $2.2 \mathrm{~mm}$ ) was used to evaluate the stricture. Under direct endoscopic vision, the mini-probe was passed through the lumen of the stricture. If the probe could not be passed across the stricture initially, a guidewire $(0.025,270 \mathrm{~cm}$, Visiglide, Olympus, United States) was inserted first using a standard cannula (Olympus, United States) and then the probe was inserted over the guidewire. Assessment of the stricture was done by direct contact method. EUS-M evaluation was carried out by a single experienced operator (JS) with experience of performing >3,500 EUS procedures. Initially, the probe was passed across the length of the stricture, and then gradually pulled proximally. Layers of the esophagus, namely the mucosa, submucosa, muscularis and the outer adventitial layers, were identified and the stratification, thickness, symmetric or asymmetric thickening, and depth of the stricture was noted in terms of involvement of the layers ( $\mathbf{F i g} \mathbf{1}$ ). The segment of the stricture with the maximum wall thickness was considered for evaluation of the characteristics and measurements.

Measurements were taken for total EWT and thickness of the involved part of the wall. Thickness was measured from the luminal mucosal layer to the outer layer of the esophagus for total wall thickness and up to the outer margin of the stricture for involved part thickness. The percentage of the esophageal wall involved by the stricture ([involved part thickness/total wall thickness ${ }^{*}$ 100) also was calculated.

\section{Endoscopic dilation}

Endoscopic dilation was done after informed consent and as an outpatient procedure ( $>$ Fig.2). Patients underwent sedation with intravenous midazolam (initially $0.5-1 \mathrm{mg}$, dose titrated to effect with cumulative dose $<5 \mathrm{mg}$ ) with/without intravenous (IV) pentazocine $(20-30 \mathrm{mg})$ before dilation. Dilation was performed using balloon dilators (CRE balloon, Boston Scientific, Marlborough, Massachusetts, United States). The diameter of the balloon was determined on the basis of the endoscopist's subjective assessment and imaging findings. The balloon was negotiated across the narrowed segment under endoscopic vision and was positioned approximately equally on either side of the narrowing and inflated by a saline-filled pressure gun (Alliance inflation device; Boston Scientifc Corp, Marlborough, Massachusetts, United States) as per manufacturer's instructions. The balloon was inflated to incremental diameters, for 60 seconds at each diameter.

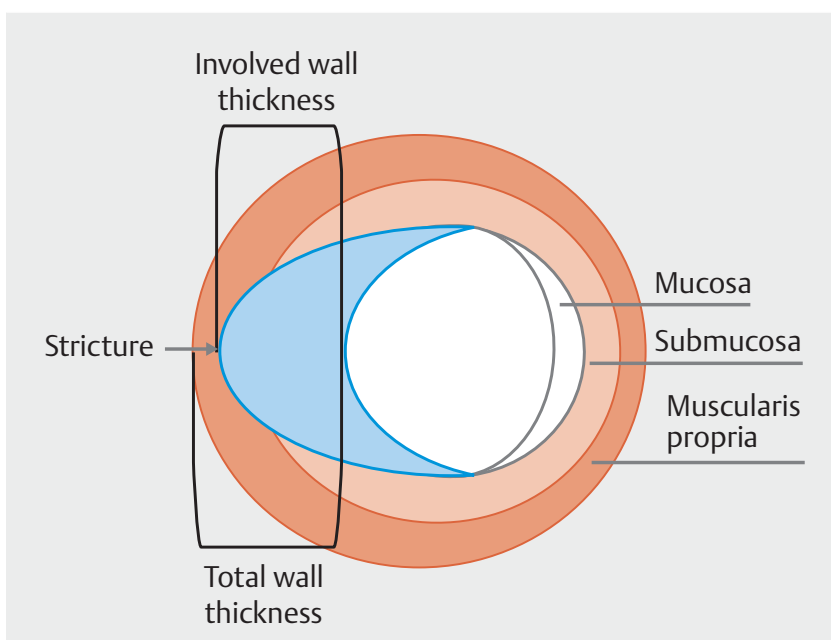

Fig. 1 Schematic diagram of the layers of the esophagus on EUS assessment. 
40 patients with 42 strictures screened $(n=42)$

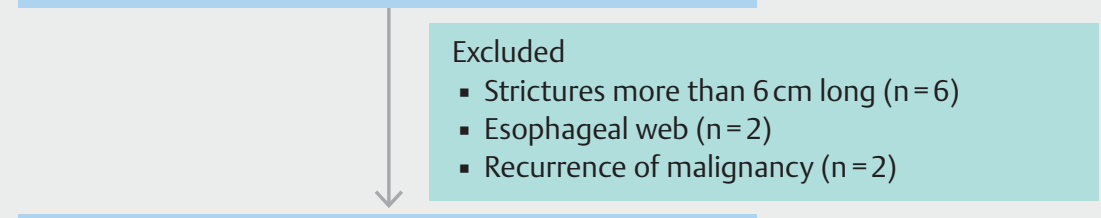

Included in study
30 patients with 32 strictures $(\mathrm{n}=32)$
Assessment
Barium esophagogram
Upper Gl endoscopy
EUS Mini-probe

\section{Excluded \\ Expired (unrelated to intervention) $(n=1)$}

Intervention done -

5 sessions of Endoscopic dilatation

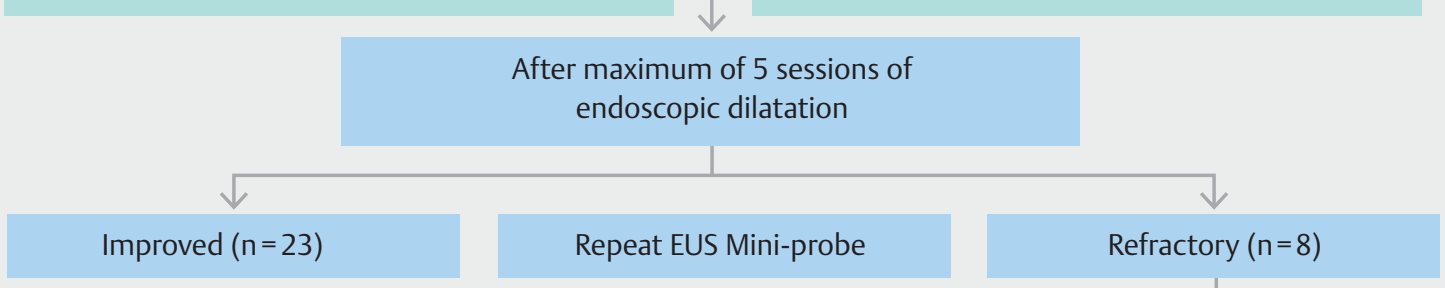

\begin{tabular}{|c|c|}
\hline $\begin{array}{l}\text { Excluded } \\
\text { Lost to follow up }(n=1)\end{array}$ & $\begin{array}{l}\text { Intervention done- } \\
\text { Endoscopic dilatation + } \\
\text { Intralesional triamcinolone } \\
\text { (5 sessions) }\end{array}$ \\
\hline$\sqrt{ }$ & $\Downarrow$ \\
\hline Improved $(n=6)$ & $\begin{array}{c}\text { Failure }(n=1) \\
\text { Referred for surgery }\end{array}$ \\
\hline
\end{tabular}

Fig. 2 Study design.

After each dilation, patients were observed for 4 hours with specific attention to the occurrence of chest pain, abdominal pain, and difficulty in breathing and hemodynamic status. Patients were discharged home the same day with instructions to immediately report if they developed any fever, chest pain, or shortness of breath. They were followed up for a period of 48 hours post-procedure via telephone calls. In the event of suspected perforation, a water-soluble contrast study was performed to document any leak, and urgent surgical consultation was sought. Patients with peptic strictures were prescribed proton pump inhibitors (PPI) besides dilation.

Dilation was repeated at 2 - to 3 -week intervals until a target diameter of $15 \mathrm{~mm}$ was achieved. Patients with refractory strictures were considered for endoscopic injection of steroids into the stricture. Triamcinolone acetonide $(80 \mathrm{mg}$, diluted $1: 1$ with saline solution) was injected with a 23 -gauge, 5 -mm-long sclerotherapy needle in aliquots of $0.5 \mathrm{~mL}$ each as described in detail elsewhere [8].

\section{Definitions}

1. Dysphagia was graded on a scale of 0 to 4. [9]

2. Clinical success (responders) was defined as resolution of difficulty in deglutition with symptomatic improvement to a dysphagia score of less than 2 and achievement of $15-\mathrm{mm}$ dilation [10].

3. Refractory stricture (RS) was defined if even after five sessions of dilation, the patient still remained symptomatic or the stricture could not be dilated to a diameter of $15 \mathrm{~mm}$ [10].

\section{Follow-up imaging}

All patients underwent repeat EUS-M assessment after the initial maximum of five sessions of dilations and were assessed for the same parameters as mentioned above. 


\section{Data analysis}

Very limited data exist on the role of EUS-M in esophageal strictures, hence this study was conducted as a proof-of-concept. Patients were grouped into responders and refractory stricture after the initial sessions (maximum five dilations). Assessment of response was done by PD and RK, who were blinded to the EUS findings. JS was blinded regarding the response.

\section{Outcome measures}

The primary outcome measure was to compare the responder and the refractory groups for EUS-M characteristics such as total esophageal wall thickness, involved esophageal wall thickness, and layers of esophageal wall involvement for their effects on response to dilation. EUS-M characteristics of the strictures based on etiology were also noted and their impact on the final outcome. The change in the involved esophageal wall thickness after the five sessions of dilation were also compared between responders and refractory group.

\section{Statistical analysis}

Data were entered in Microsoft Excel and analyzed using SPSS software version 23.0 (SPSS Inc., Chicago, Illinois, United States). Quantitative variables were represented using measures of central location like mean/median/measures of dispersion (standard deviation or standard error). Continuous variables were compared using the Student's $t$ test. Dichotomous variables were compared using Chi squared test. $P<0.05$ was considered statistically significant. Repeated measurement of ANOVA was used for relationship between EUS-M layers of esophageal wall involvement and outcome. A receiver operating characteristic curve was plotted and a cut-off of the involved wall thickness for predicting response to dilation was calculated. Based on a previous study [6], the dilation requirement for strictures involving muscularis propria and those not involving it were 6.30 vs 2.67 sessions. Thus, with $80 \%$ power and alpha error estimation of $5 \%$, a sample size of 14 , with seven having muscularis involvement and seven without, was estimated.

\section{Results}

Forty patients with benign ES were screened to be enrolled in this study. Of the 40 patients screened, eight were excluded (6 had strictures $>6 \mathrm{~cm}$ in length and 2 had esophageal webs). Finally, 30 patients with 32 strictures were included in the study ( Fig. 2).

Of the 30 patients, 17 were females; the age ranged from 19 to $71 \mathrm{yr}$ (mean $47.16 \pm 15.88 \mathrm{yr}$ ). The etiology was anastomotic (after esophago-gastric or esophago-colonic anastomosis), $n=$ 14 (13 for carcinoma esophagus and 1 for corrosive injury); caustic, $n=6$ with eight strictures; peptic, $n=7$ and drug-induced (nonsteroidal anti-inflammatory drugs [NSAIDS]), $n=2$. Median time from symptom onset to endoscopic assessment was 3 months (IQR 10). Of the seven cases of peptic stricture, three had ulceration and the remaining four did not. None of the other strictures had hyperemia or ulceration. Mean length of strictures on barium esophagography was $3.45 \mathrm{~cm}$ (standard deviation $4.6 \mathrm{~cm}$.), without any ulceration or intra-mural pseudo-diverticula. The most common site of stricture was the upper esophagus $(14 ; 45.2 \%)$ followed by middle and lower third of the esophagus (6 each; $19.4 \%$ ).

After the initial phase of a maximum of five sessions of dilations as described above, 23 patients were classified as responders and eight had refractory strictures. One patient expired due to an unrelated cause and was excluded from the final analysis. Of the eight refractory strictures, six improved after an additional three to five sessions of dilation with intralesional triamcinolone, while one underwent surgery and one was lost to follow up ( $\triangleright$ Fig. 2 ). The response to dilation is summarized in Table 1.

\section{EUS mini-probe assessment}

Of the 30 patients with 32 strictures, EUS-M stricture assessment was done in 31 strictures. This included two patients with two strictures each, whose individual strictures were analyzed separately at the start of intervention and on follow-up. In one patient, EUS-M assessment could not be done as the patient did not give consent for the same.

\section{EUS mini-probe characteristics based on etiology of stricture}

- Table 2 shows details of EUS-M evaluation in patients with different etiology. Corrosive strictures had the highest total esophageal wall thickness $(4.66 \pm 1.34 \mathrm{~mm})$ followed by anastomotic $(4.00 \pm 1.54 \mathrm{~mm})$ and peptic strictures $(3.44 \pm 1.3 \mathrm{~mm}) ; P=$ 0.275 . The two patients with NSAID-induced strictures had wall thickness of $9.2 \mathrm{~mm}$ and $3.2 \mathrm{~mm}$. Patients with corrosive strictures had the most involved esophageal wall thickness and percentage of the esophageal wall involved followed by anastomotic and peptic strictures ( $P=0.026$ and $P=0.021$, respectively).

\section{EUS mini-probe characteristics and outcome}

EUS-M findings of 30 strictures were compared between responders and non- responders ( Table 3 ). D Table 3 shows that baseline EUS features of the strictures such as total esophageal wall thickness and involved esophageal wall thickness did not differ between those who improved compared to those

\begin{tabular}{|l|l|l|l|l|}
\hline \multicolumn{5}{|l|}{ Table 1 Response of dilations according to etiology. } \\
\hline $\begin{array}{l}\text { Type of } \\
\text { Stricture }\end{array}$ & $\begin{array}{l}\text { No. of } \\
\text { Patients/ } \\
\text { Stric- } \\
\text { tures }\end{array}$ & $\begin{array}{l}\text { Respon- } \\
\text { ders (\%) }\end{array}$ & $\begin{array}{l}\text { No. of Dila- } \\
\text { tions to 15 } \\
\text { mm (mean } \\
\text { no.to reach } \\
\text { Com- }\end{array}$ & $\begin{array}{l}\text { plica- } \\
\text { tions }\end{array}$ \\
\hline Anastomotic & $13 / 13$ & $8(61.5 \%)$ & 4.28 & nil \\
\hline Corrosive & $6 / 8$ & $6(75 \%)$ & 4 & nil \\
\hline Peptic & $7 / 7$ & $100 \%$ & 2.42 & nil \\
\hline NSAIDs & $2 / 2$ & $50 \%$ & 1.5 & nil \\
\hline NSAIDs, non-steroidal anti-inflammatory drugs & & \\
\hline
\end{tabular}


- Table2 Comparison of EUS findings in esophageal strictures based on etiology.

\begin{tabular}{|l|l|l|l|}
\hline EUS mini-probe Findings ${ }^{*}$ & $\begin{array}{l}\text { Anastomotic } \\
\text { stricture (n=13) }\end{array}$ & $\begin{array}{l}\text { Corrosive } \\
\text { stricture (n=8) }\end{array}$ & $\begin{array}{l}\text { Peptic } \\
\text { stricture (n=7) }\end{array}$ \\
\hline Total esophageal wall thickness (mean \pm SD in mm) & $4.00 \pm 1.54$ & $4.66 \pm 1.34$ & $3.44 \pm 1.3$ \\
\hline Involved esophageal wall thickness (mean \pm SD in mm) & $2.73 \pm 1.7$ & $3.51 \pm 1.36$ & $1.39 \pm 0.62$ \\
\hline $\begin{array}{l}\text { Percentage of esophageal wall involved by the stricture } \\
\text { (mean } \pm \text { SD in percentage) }\end{array}$ & $65.54 \pm 25.4$ & $76.38 \pm 26.2$ & $40.71 \pm 14.6$ \\
\hline $\begin{array}{l}\text { EUS, endoscopic ultrasound; SD, standard deviation. } \\
\text { * Two patients had nonsteroidal anti-inflammatory drug-related stricture and are not shown in this table. }\end{array}$ & 0.026 \\
\hline
\end{tabular}

- Table 3 Comparison of EUS mini-probe findings between responders versus refractory strictures.

\begin{tabular}{|l|l|l|}
\hline EUS mini-probe findings & Responders $(\mathbf{n = 2 2})$ & Refractory (n=8) \\
\hline Total esophageal wall thickness (mean \pm SD in mm) & $4.30 \pm 1.91$ & $3.78 \pm 0.92$ \\
\hline Involved esophageal wall thickness (mean \pm SD in mm) & $2.51 \pm 1.82$ & $2.87 \pm 1.44$ \\
\hline Percentage of esophageal wall involved by the stricture (mean \pm SD in percentage) & $55.23 \pm 23.23$ & $72.50 \pm 27.87$ \\
\hline EUS, endoscopic ultrasound; SD, standard deviation. & & .613 \\
\hline
\end{tabular}

who did not. The percentage of esophageal wall involved by stricture showed a trend towards significance with a higher percentage involvement seen in those patients who developed refractory strictures.

However, when a cut-off of $2.85 \mathrm{~mm}$ of the involved wall thickness was used, there was a statistically significant difference in mean number of dilations needed for stricture resolution ( $\vee$ Fig.3). Strictures with involved wall thickness $\geq 2.85$ $\mathrm{mm}$ required a mean of 5.10 dilations compared to 2.83 for those $<2.85 \mathrm{~mm}(P=0.011)$. The cut-off of $2.85 \mathrm{~mm}$ for involved wall thickness had a sensitivity of $67 \%$ and specificity of $73 \%$ for predicting requirement of more than five sessions of intervention for stricture resolution.

Patients were categorized into two groups based on EUS-M assessment of percentage esophageal wall involvement by the

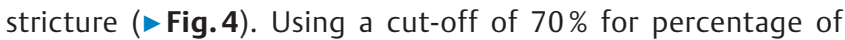
esophageal wall involved by stricture, there was a statistically significant difference between responders and non-responders. While $85.7 \%$ patients with $<70 \%$ involvement responded to five sessions of dilation, response was seen in only $44.4 \%$ for those with involvement $\geq 70 \%(P=0.019)$.

\section{Impact of esophageal wall layer involvement by stricture on outcome}

Depth of esophageal wall involved by the stricture was assessed by EUS-M in terms of number of layers affected before start of intervention. Only mucosal involvement was noted in 15 strictures, mucosal and submucosal involvement in nine and all three layers involved in six ( $\mathbf{F i g . 5}$ ). We analyzed response based on the layers of involvement. More dilations were needed for symptom resolution with increasing depth of involvement of esophageal layers from mucosa to muscularis propria ( $\triangleright$ Table 4 ). The responder group had more strictures with only mucosal involvement (13;59.1\% vs. $2 ; 25 \%)$ and fewer with all layer involvement

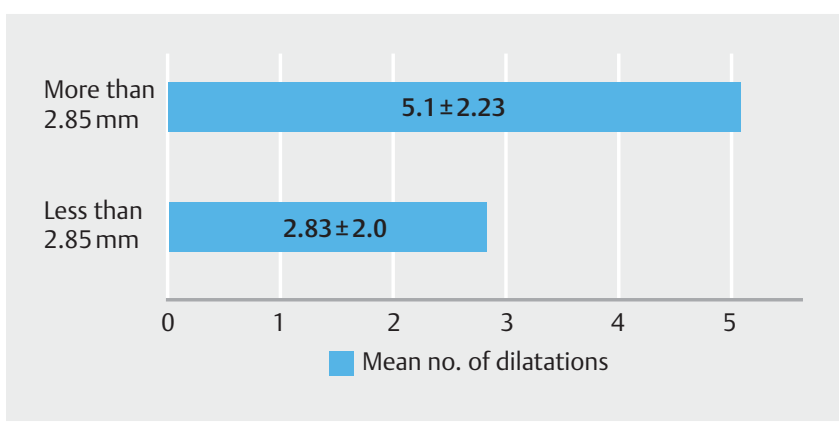

Fig. 3 Comparison of mean number of dilations needed for stricture resolution when a cut-off of involved esophageal wall thickness of $2.85 \mathrm{~mm}$ is used.

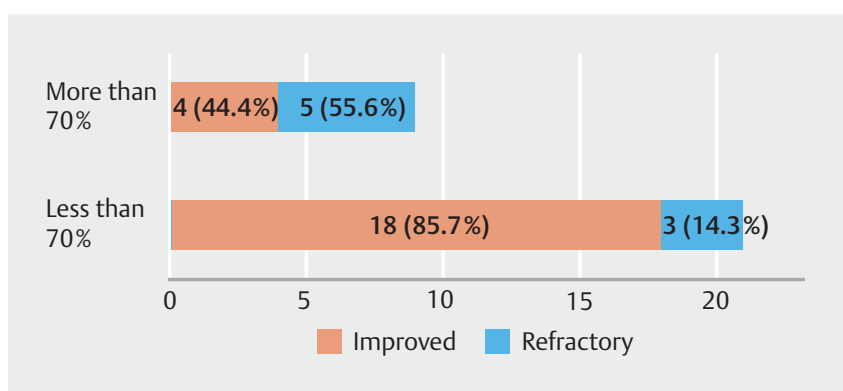

Fig. 4 Comparison of percentage of wall involvement between improved strictures and refractory strictures.

(3; $13.6 \%$ vs. $3 ; 37.5 \%$ ) compared to refractory group although the difference did not reach significance $(P=0.077)$. 

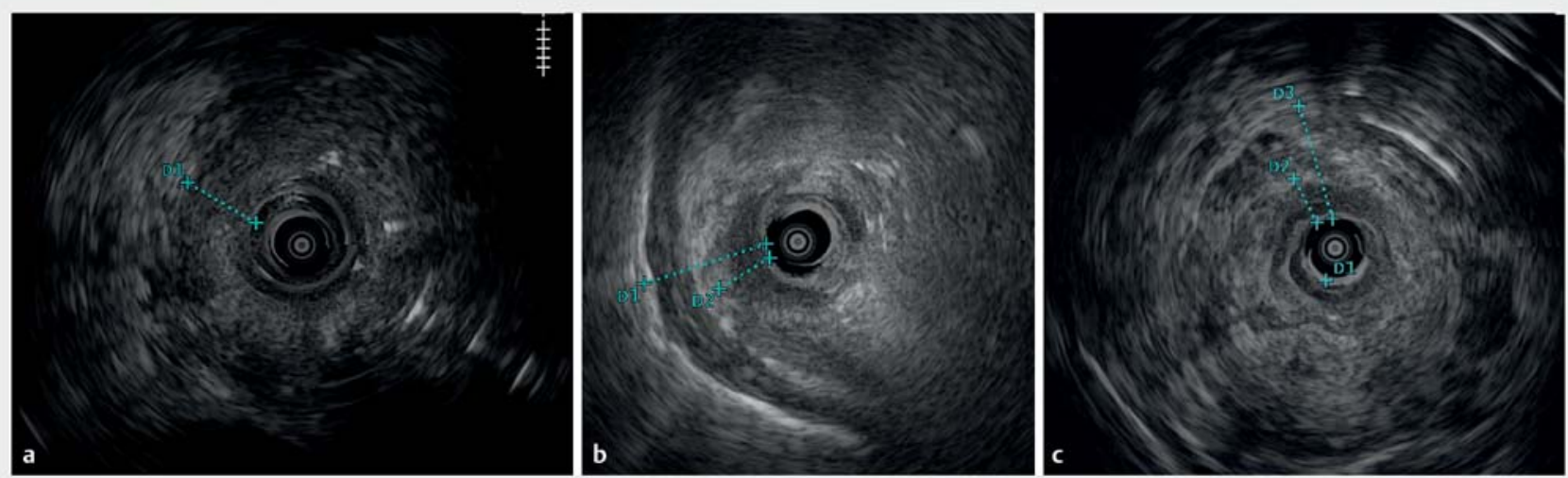

- Fig. 5 EUS mini-probe images of strictures. a Corrosive stricture involving all layers of the esophageal wall, D1 is the involved wall thickness$3.1 \mathrm{~mm}$. b Corrosive stricture with involvement till the submucosa, D2 is the involved esophageal wall thickness $-2.2 \mathrm{~mm}$. and D1 is the total wall thickness $-4.8 \mathrm{~mm}$. c Peptic stricture involving the mucosa, involved wall thickness is D2 $-1.9 \mathrm{~mm}$. and D3 is total esophageal wall thickness $4.6 \mathrm{~mm}$.

- Table 4 Number of dilations needed for clinical response according to the layers of esophageal wall involved.

\begin{tabular}{|c|c|c|c|}
\hline EUS mini-probe layers of esophageal wall involvement & Total number & Mean number of dilations for clinical response ( \pm SD) & $P$ value \\
\hline Layer 1 = only mucosa (no.) & 15 & $2.14( \pm 1.83)$ & \multirow[t]{3}{*}{.001} \\
\hline Layer 2 = mucosa + submucosa (no.) & 9 & $4.78( \pm 1.85)$ & \\
\hline Layer $3=$ mucosa + submucosa + muscularis propria (no.) & 6 & $5.80( \pm 1.64)$ & \\
\hline
\end{tabular}

\section{Change in the esophageal wall layer thickness after dilation}

Change in EWT was assessed by EUS-M after five sessions of intervention. Repeat EUS assessment was available for 20 strictures and comparison between those who responded and those who were refractory is shown in $>$ Table 5 . Mean change in total EWT was significantly higher in the responder group compared to the refractory group ( 1.32 vs $0.200 ; P=0.023$ ) with greater percentage change in the wall thickness $(29.1 \%$ vs $5.7 \%$; $P=$ $0.003)$.

\section{Discussion}

In this study, we assessed the utility of EUS-M in predicting response of esophageal strictures to endoscopic dilation in a cohort of 28 patients with 30 strictures. Although total EWT on EUS among different etiologies of stricture did not differ, but there were significant differences based on involved wall thickness and percentage of esophageal wall involvement. Corrosive strictures had the most involvement of wall thickness and percentage of esophageal wall involvement followed by anastomotic strictures, while peptic strictures had the lowest value. Mean number of dilations required for stricture resolution was found to be significantly dependent on the layers of the wall involved.

Stricture formation occurs due to fibrous tissue production and collagen deposition in the esophageal wall, leading to nar-
- Table 5 Comparison of change in esophageal wall thickness with intervention between responder and refractory groups.

\begin{tabular}{|l|c|c|c|}
\hline EUS mini-probe findings & $\begin{array}{l}\text { Responder } \\
\mathbf{N}=\mathbf{1 4}\end{array}$ & $\begin{array}{l}\text { Refractory } \\
\mathbf{N = 6}\end{array}$ & $\boldsymbol{P}$ value \\
\hline $\begin{array}{l}\text { Mean change in total } \\
\text { esophageal wall thickness } \\
\text { in mm ( } \pm \text { SD) }\end{array}$ & $1.32 \pm 1.1$ & $\begin{array}{l}0.200 \pm 0.12 \\
( \pm 1.08)\end{array}$ & 0.023 \\
\hline $\begin{array}{l}\text { Mean Percentage change } \\
\text { in esophageal wall thick- } \\
\text { ness in \% ( } \pm \text { SD) }\end{array}$ & $29.1 \pm 16.3$ & $5.7 \pm 3.13$ & 0.003 \\
\hline \begin{tabular}{l} 
EUS, endoscopic ultrasound, SD, standard deviation. \\
\hline
\end{tabular} & \\
\hline
\end{tabular}

rowing of the esophageal lumen. Both circumferential and longitudinal collagen deposition has been demonstrated after corrosive esophageal injury [11]. The esophageal wall gets markedly thickened secondary to this deposition [4]. Similarly, anastomotic strictures develop from the ischemic injury incurred, leading to similar collagen deposition and fibrosis [12]. UIceration, hyperemia, and other factors can confound the findings of wall thickness or involvement. However, only three patients with peptic strictures in the current study had ulceration. None of the patients in the corrosive or anastomotic group had ulceration. In fact, corrosive and anastomotic strictures are known to be complex strictures. Earlier studies using EUS did show that corrosive and post-radiation strictures have thicker 
EWT compared to peptic strictures [6,7]. Using EUS-M, we found that while the total EWT was no different among patients with different etiologies, the involved EWT was higher in corrosive strictures $(3.51 \pm 1.36 \mathrm{~mm})$ than in anastomotic strictures $(2.73 \pm 1.7 \mathrm{~mm})$ and peptic strictures $(1.39 \pm 0.62 \mathrm{~mm})$. The percentage of involved EWT was also highest in corrosive strictures followed by anastomotic and peptic strictures.

Prediction of stricture resolution following dilation has been the subject of much interest as it may be helpful in predicting outcome and counselling patients. Moreover, rescue measures used for refractory strictures could be employed upfront in predicted poor responders. Lahoti et al evaluated the role of CT imaging in prognosticating corrosive esophageal strictures in 21 patients [4]. They found that patients with maximal wall thickness $\geq 9 \mathrm{~mm}$ required more dilations. However, a recent study of 64 patients with corrosive strictures showed that median CT esophageal wall thickness was $7 \mathrm{~mm}$ (range 3-22 mm) and that it did not predict technical or clinical success, refractory or recurrent strictures and adverse events of endoscopic dilation [5]. CT can evaluate overall wall thickness, but it cannot delineate the wall layers and hence their degree of involvement. Therefore, the role of EUS is important because it can image layers of the wall of the esophagus and thus the depth and degree of involvement.

Radial EUS has been used to assess benign ES in 27 patients [6] in one study and it was found that corrosive and post-radiation strictures had significantly greater wall thickness compared to peptic strictures. Moreover, depth of wall involvement on EUS predicted endoscopic dilation response. However, this assessment could be done only from the mouth of the stricture. Adequate examination of the whole length of the stricture is needed for effective measurement of the EWT and the layers involved as evidently these strictures need not be uniform in their depth of involvement along the longitudinal axis. For that to be done with radial EUS, the stricture has to be dilated. That might not only distort the subsequent image acquisition, but even after dilation, the sturdy echoendoscope might not be successfully maneuvered across the stricture. EUS-M has clear advantages in this regard, as it can be easily passed across tight strictures without dilation. In a recent study, EUS-M was used to assess indeterminate strictures wherein only total wall thickness was assessed and the conclusion was that wall thickness $\geq 9 \mathrm{~mm}$ was suggestive of malignancy [13]. In the only other study of EUS-M for benign ES, the authors only looked into maximum EWT and layers of the wall involved. Both those parameters were found to correlate with increased requirement for dilation [7].

Our study, using EUS-M, demonstrated that rather than the total wall thickness, it is the depth of esophageal wall involved by the stricture that is predictive of treatment response. We looked at total EWT, involved EWT, and percentage of the wall involved in patients who responded and those who had refractory strictures. There was no difference in any of the three measurements between the two groups although there was a trend towards a higher percentage of esophageal wall involved in the refractory strictures. Moreover, $>70 \%$ esophageal wall involvement correlated with number of dilations required. Ana- lyzing further, we found that depth of wall involvement in terms of the layers of wall did correlate with the outcome. Patients with only mucosal fibrosis had the best response while those with involvement of muscularis propria had the worst. This observation could only be made by using EUS-M and not with any other imaging. Esophageal wall edema can confound the findings on wall thickness. However, all patients in the current study were in chronic phase ( $>3$ months) and thus had fibrotic strictures, evident from the scarred tissue on endoscopy, rather than edema. Moreover, edema can be delineated on EUS as hypoechoic areas within the layers, which was not present in any of the cases in the current study. Thus, we believe that edema did not contribute to esophageal wall involvement in any of our patients.

This relates to the fact that depth of involvement of a stricture, which is an indirect clue to the depth of injury, determines the "refractoriness" of the stricture. The deeper the involvement, the greater the fibrosis and more difficult it is to break it. Corrosive strictures are known to be refractory due to the deeper tissue injury, a fact that has been highlighted in the current study. Anastomotic stricture, being ischemic in nature, corresponds to similar deep involvement [12]. Peptic strictures, on the other hand, are usually short $(<1 \mathrm{~cm})$ and start with edema associated with chronic inflammation and eventually lead to fibro-collagen deposition [14]. They are usually simple strictures and rarely tends to be refractory [2].

An interesting observation was repeat imaging in 20 patients that showed greater change in total EWT and percentage change in EWT in responders as compared to refractory strictures. The major factor contributing to the thickness of the involved segment was the extent of fibrosis. More effective breakage of this fibrotic tissue leads to better treatment response and indirectly reflects greater change in wall thickness after dilation. Our study is the first to demonstrate this phenomenon objectively, that is, greater change in wall thickness occurs among responders compared to those who are refractory.

This was the first study to include a detailed evaluation of EUS-M in patients with benign ES in terms of total EWT, involved EWT, and depth of involvement, its impact on the outcome and also to compare the three different etiologies influencing characteristics of strictures. Moreover, the dynamics of the stricture characteristics before and after dilation and its impact were demonstrated. In a sense, in patients with deeper involvement, as assessed on EUS-M, and thus expected poor outcome with conventional dilation techniques, additional measures such as stents or surgery can be undertaken up front. Moreover, recent advances in management of difficult strictures and complete esophageal obstruction involve techniques such as open per-oral endoscopic myotomy (O-POEM) and peroral endoscopic tunneling for restoration of esophagus (POETRE) [15]. In these situations, involvement of muscle layer by EUS-M can help predict the feasibility of these techniques [16]. We propose that, with adequate validation, the concept of EWT assessment prior to subjecting patients to dilation can be incorporated in an algorithm to guide optimum manage- 
ment of ES, thus avoiding the tedious route of initial conventional dilation regimens.

The limitations of this study were that the sample size was small. Moreover, repeat EUS-M evaluation was available only for 20 strictures. Larger studies are needed to consolidate the findings of the current study. Our study did not include radiation strictures, which is an important cohort of refractory cases and warrants further study along the same lines. Stricture diameter assessment requires more objective measurement, such as with a barium pill.

\section{Conclusion}

In conclusion, this was the largest study to evaluate the role of EUS-M for predicting response of benign ES to endo-therapy. EUS-M, which can be negotiated across the stricture segment, provides high-resolution images and is a useful tool for adequately assessing stricture dynamics. Corrosive and anastomotic strictures have greater depth involvement compared to peptic strictures, hence their expected refractoriness to therapy. Depth of involvement by a stricture and the layers of the esophageal wall involved rather than the esophageal wall thickness predict whether a stricture will respond to endo-therapy.

Competing interests

The authors declare that they have no conflict of interest.

\section{References}

[1] Pereira-Lima JC, Ramires RP, Zamin I et al. Endoscopic dilation of benign esophageal strictures: report on 1043 procedures. Am J Gastroenterol 1999; 94: 1497-1501

[2] Lew R], Kochman ML. A review of endoscopic methods of esophageal dilation. J Clin Gastroenterol 2002; 35: 117-126
[3] Poincloux L, Rouquette O, Abergel A. Endoscopic treatment of benign esophageal strictures: a literature review. Expert Rev Gastroenterol Hepatol 2017; 11: 53-64

[4] Lahoti D, Broor SL, Basu PP et al. Corrosive esophageal strictures: predictors of response to endoscopic dilation. Gastrointest Endosc 1995; 41: 196-200

[5] Gupta P, Gulati A, Reddy YR et al. Does esophageal wall thickness on computed tomography predict response to endoscopic dilatation in patients with corrosive esophageal strictures? JGH Open 2019; 3: 405-408

[6] Rana SS, Bhasin DK, Singh K. Role of endoscopic ultrasonography (EUS) in management of benign esophageal strictures. Ann Gastroenterol 2011; 24: 280-284

[7] Rana SS, Sharma R, Kishore K et al. High-frequency miniprobe endoscopic ultrasonography in the management of benign esophageal strictures. Ann Gastroenterol 2020; 33: 25-29

[8] Kochhar R, Makharia GK. Usefulness of intralesional triamcinolone in treatment of benign esophageal strictures. Gastrointest Endosc 2002; 56: 829-834

[9] Atkinson M, Ferguson R, Ogilvie AL. Management of malignant dysphagia by intubation at endoscopy. J R Soc Med 1979; 72: 894-897

[10] Kochman ML, McClave SA, Boyce HW. The refractory and the recurrent esophageal stricture: a definition. Gastrointest Endosc 2005; 62: 474-475

[11] Johnson EE. A study of corrosive esophagitis. Laryngoscope 1963; 73 : 1651-1696

[12] Cassivi SD. Leaks, strictures, and necrosis: a review of anastomotic complications following esophagectomy. Semin Thorac Cardiovasc Surg 2004; 16: 124-132

[13] Rana SS, Sharma R, Gupta R. High-frequency miniprobe endoscopic ultrasonography for evaluation of indeterminate esophageal strictures. Ann Gastroenterol 2018; 31: 680-684

[14] Pregun I, Hritz I, Tulassay Z et al. Peptic esophageal stricture: medical treatment. Dig Dis 2009; 27: 31-37

[15] Perbtani Y, Suarez AL, Wagh MS. Emerging techniques and efficacy of endoscopic esophageal reconstruction and lumen restoration for complete esophageal obstruction. Endosc Int Open 2016; 4: E136E142

[16] Wu C, Luo S, Guo L et al. Open peroral endoscopic myotomy for refractory benign esophageal stricture. Endoscopy 29.012020 : doi:10.1055/a-1089-7551 